\title{
Upaya Meningkatkan Kemampuan Guru Dalam Menyusun Rencana Pelaksanaan Pembelajaran (RPP) Melalui Work Shop di TK Srawong Bocah Yogyakarta
}

\author{
Titik Mulat Widyastuti*, Syahria Anggita Sakti \\ Universitas PGRI Yogyakarta, Yogyakarta, Indonesia \\ *Coresponding Author: titikmulatupy@gmail.com \\ Dikirim: 17-01-2022; Direvisi: 19-01-2022; Diterima: 20-01-2022
}

\begin{abstract}
Abstrak: Berdasarkan hasil pengamatan yang telah dilakukan, terdapat kesulitan yang dihadapi guru-guru TK Inklusi Srawong Bocah dalam menyusun perangkat pembelajaran yakni rencana pelaksanaan pembelajaran (RPP). Kendala tersebut menjadi satu masalah yang sering dihadapi dalam pelaksanaan pembelajaran para guru. Hampir $75 \%$ guru-guru di KB TK Inklusi Srawung Bocah belum mempunyai kompetensi sebagai pendidik PAUD. Mereka berasal dari lulusan yang bukan dari latar belakang kependidikan. Kegiatan work shop guru PAUD ini bertujuan untuk meningkatkan kemampuan guru-guru PAUD dalam menyusun rencana pelaksanaan pembelajaran (RPP) agar dapat menstimulasi seluruh aspek perkembangan anak (aspek nilai agama dan moral, fisik motorik, kognitif, bahasa, sosial emosional, dan seni) untuk diterapkan pada pendidikan anak di lembaga PAUD. Metode yang digunakan dalam kegiatan ini yaitu metode tindakan kepengawasan yang dilaksanakan selama 2 siklus. Setiap siklusnya terdiri dari 4 tahapan kegiatan yaitu perencanaan, pelaksanaan, pengamatan atau observasi, dan evaluasi (refleksi). Hasil workshop menunjukkan bahwa kopetensi guru-guru PAUD di KB TK Srawong Bocah dalam membuat rencana pelaksanaan pembelajaran meningkat setelah mengikuti kegiatan workshop penyusunan RPP.
\end{abstract}

Kata Kunci: Work Shop; Guru PAUD; Rencana Pelaksanaan Pembelajaran

\begin{abstract}
Based on the observations that have been made, there are difficulties faced by the teachers of the Inclusive Kindergarten of Srawong Bocah in preparing learning tools, namely the lesson implementation plan (RPP). This obstacle is a problem that is often faced in the implementation of teacher learning. Almost $75 \%$ of the teachers in the KB TK Inclusive Srawung Bocah do not yet have the competence as PAUD educators. They come from graduates who are not from an educational background. This PAUD teacher work shop activity aims to improve the ability of PAUD teachers in preparing lesson plans (RPP) in order to stimulate all aspects of children's development (aspects of religious and moral values, physical motoric, cognitive, language, social emotional, and art) to applied to children's education in PAUD institutions. The method used in this activity is the supervisory action method which is carried out for 2 cycles. Each cycle consists of 4 stages of activity, namely planning, implementation, observation or observation, and evaluation (reflection). The results of the workshop showed that the competence of PAUD teachers in KB TK Srawong Bocah in making lesson plans increased after participating in the RPP preparation workshop.
\end{abstract}

Keywords: Workshops; PAUD teachers; Lesson plan

\section{PENDAHULUAN}

Guru merupakan salah satu profesi yang dalam pelaksanaan profesinya membutuhkan penguasaan dalam berbagai kopetensi. Salah satu kopetensi yang 
harus dikuasai adalah kompetensi pedagogik, yang diantaranya indikatornya adalah kemampuan merancang pembelajaran. Rancangan pembelajaran dalam bidang pendidikan anak usia dini, dinamakan dengan rencana pelaksanaan pembelajaran atau RPP, baik rencana pembelajaran mingguan maupun rencana pembelajaran harian. Guru adalah pendidik professional dengan tugas utama mendidik, mengajar dan membimbing, mengarahkan, melatih, menilai dan mengevaluasi peserta didik pada pendidikan anak usia dini jalur pendidikan formal, pendidikan dasar, dan pendidikan menengah (Undang-Undang No 14 Tahun 2005 tentang Guru dan Dosen Bab 1 pasal 1). Guru merupakan kunci penting dalam keberhasilan memperbaiki mutu pendidikan. Salah satu ciri dari mutu pendidikan yang baik adalah terciptanya proses pembelajaran yang baik pula melalui perencanaan, pelaksanaan maupun evaluasi.

Rencana pelaksanaan pembelajaran (RPP) merupakan rencana pembelajaran yang menggambarkan prosedur dan pengorganisasian pembelajaran siswa untuk mencapai satu kompetensi dasar (KD) yang akan dilakukan guru dalam satu lebih pertemuan proses belajar mengajar dikelas atau tempat pembelajaran lainnya. Rencana pelaksanaan pembelajaran (RPP) bisa disusun dengan komponen yang minimal, tetapi lebih baik dengan komponen yang lengkap dan dengan susunan yang sistematis sesuai urutan pelaksanaannya, karena pada hakekatnya rencana pelakasanaan pembelajar (RPP) merupakan scenario pembelajaran, sehingga siapapun pemerannya bisa melakukannya karena segalanya sudah ada pada scenario tersebut (Ardiawan, 2020). Rencana pelaksanaan pembelajaran (RPP) yang lengkap terdiri dari (Permendiknas No. 41 Tahun 2007), Tentang Standar Proses) ,meliputi , (1) Identitas, (2) Standar Kompetensi (SK), (3) Kompetensi Dasar (KD) , (4) Alokasi waktu, (5) Indikator Ketercapaian, (6) Tujuan Pembelajaran (7) Materi Pembelajaran, (8) Metode Pembelajaran, (9) Kegiatan Pembelajaran, (10) Sumber Belajar), (11) Penilaian.

Menurut (Nurmajaya, 2021) mengemukakan bahwa perangkat pembelajaran adalah sejumlah bahan, alat, media, petunjuk dan pedoman yang digunakan dalam proses pembelajaran. Perangkat pembelajaran menjadi tolak ukur dalam pelaksanaan proses pembelajaran. Guru merupakan kunci penting dalam keberhasilan memperbaiki mutu pendidikan. Salah satu ciri dari mutu pendidikan yang baik adalah terciptanya proses pembelajaran yang baik mulai dari perencanaan, pelaksanaan maupun evaluasi. Rencana Pelaksanaan Pembelajaran (RPP) adalah pegangan guru dalam mengajar di dalam kelas. Seorang guru harus mampu dalam merencanakan, melaksanakan proses pembelajaran yang bermutu, serta menilai dan mengevalusi hasil pembelajaran (Syaodih et al., 2020). Pelaksanaan pembelajaran yang bermutu tentu terkait dengan kesiapan guru seperti pemilihan metode, ketersediaan media, dan kesiapan peserta didik. Berdasarkan hasil penelitian dari (Tirtayani et al., 2019) menunjukkan bahwa kesiapan guru kelas dalam memberikan pelayanan terhadap anak di kelas belum optimal. Oleh karena itu, kesiapan guru perlu ditingkatkan sehingga guru mampu memberikan pembelajaran yang bermutu dan professional sesuai dengan kurikulum yang berlaku.

Berdasarkan hasil pengamatan pada kenyataannya terdapat kesulitan yang dihadapi guru-guru TK Inklusi Srawong Bocah dalam menyusun perangkat pembelajaran yakni rencana pelaksanaan pembelajaran (RPP). Kendala tersebut menjadi satu masalah yang sering dihadapi dalam kehidupan pembelajaran para guru, 
hampir 75\% guru-guru di KB TK Inklusi Srawung Bocah belum mempunyai kopetensi sebagai pendidik PAUD mereka berasal dari lulusan yang bukan dari pendidikan (Anggreni, 2017). Banyaknya kendala dalam menyusun rencana pelaksanaan pembelajaran menyebabkan guru menjadi kurang maksimal dalam proses pembelajarn dikelas. Sehingga banyak guru hanya copi paste dari rencana pembelajaran sebelumnya. Pada hal sebagaimana yang kita ketahui bahwa seorang guru diharuskan dan diwajibkan untuk menyusun rencana pelaksanaan pembelajaran sesuai dengan amanah Undang-Undang. Fakta ini tentunya sangat mengawatirkan, karena kalau kondisi ini tidak segera diatasi dikhawatirkan akan berdampak pada menurunnya kualitas pembelajaran yang dilaksanakan oleh para guru-guru tersebut. Karena dengan menurunnya kualitas pembelajaran anak disekolah dikawatirkan akan menurunkan kwalitas hidup selanjutnya. Hal tersebut menunjukkan bahwa kesiapan guru kelas dalam memberikan pelayanan terhadap anak di kelas belum optimal.

Oleh karena itu, kesiapan guru perlu ditingkatkan sehingga guru mampu menyusun rancangan pembelajaran yang bisa menstimulasi seluruh aspek perkembangan anak (aspek nilai agama dan moral, fisik motorik, kognitif, bahasa, sosial emosional, dan seni dan memilih topik atau tema pembelajaran yang dekat dengan lingkungan dan budaya anak. Setelah pengabdi melakukan identifikasi faktor penyebab masalah tersebut maka pengabdi memilih metode work shop untuk meningkatkan kompetensi guru PAUD dalam menyusun rencana pelaksanaan pembelajaran (RPP). Berdasarkan permasalahan yang ditemukan di lapangan pengabdi tertarik untuk melaksanakan pengabdian masyarakat dengan judul "Upaya Meningkatkan Kemampuan Guru PAUD Dalam Menyusun Rencana Pelaksanaan Pembelajaran (RPP) Melalui Work Shop di TK Srawong Bocah Yogyakarta.

\section{KAJIAN TEORI}

Kegiatan proses belajar mengajar harus menggunakan rencana pelaksanaan pembelajaran (RPP) agar proses belajar mengajar memenuhi syarat dalam mengajar. Sebagaimana dijelaskan (Sutarto \& Syarifuddin, 2013; Nazara \& Ahmad, 2019) rencana pelaksanaan pembelajaran adalah rencana yang menggambarkan prosedur dan pengorganisasian pembelajaran untuk mencapai suatu kompetensi dasar yang ditetapkan dalam standar isi dan dijabarkan dalam silabus. Lingkup rencana pembelajaran paling luas mencangkup satu kompotensi dasar yang terdiri atas 1 indikator atau beberapa indikator untuk satu kali pertemuan atau lebih. Guru merancang penggalan RPP untuk setiap pertemuan yang disesuaikan dengan penjadwalan di satuan pendidikan. Sebagaimana dalam Permendikbud No 22 (2016 hlm.6) Rencana Pelaksanaan Pembelajaran (RPP) adalah rencana kegiatan pembelajaran tatap muka untuk satu pertemuan atau lebih. RPP dikembangkan dari silabus untuk mengarahkan kegiatan pembelajaran peserta didik dalam upaya mencapai Kompetensi Dasar (KD). Setiap pendidik pada satuan pendidikan berkewajiban menyusun RPP secara lengkap dan sistematis agar pembelajaran berlangsung secara interaktif, inspiratif, menyenangkan, menantang, efisien, memotivasi peserta didik untuk berpartisipasi aktif, serta memberikan ruang yang cukup bagi prakarsa, kreativitas, dan kemandirian sesuai dengan bakat, minat, dan perkembangan fisik serta psikologis peserta didik (Pamungkas et al., 2016; Susanto et al., 2021). RPP disusun berdasarkan KD atau subtema yang dilaksanakan kali pertemuan atau lebih. 


\section{METODE PELAKSANAAN KEGIATAN}

Pengabdian masyarakat ini diselenggarakan di KB-TK Inklusi Srawung Bocah yang beralamat di Sumberan RT 04 Jadan Tamantirto Kasihan Bantul Yogyakarta. Tujuan untuk mendampingi guru dalam menyusun rancangan rencana pelaksanaan pembelajaran (RPP) yang disesuaikan dengan pembelajaran yang menstimulasi seluruh aspek perkembangan anak. Adapun target luaran kegiatan ini agar guru-guru memiliki pengetahuan terkait pembelajaran yang menstimulasi seluruh aspek perkembangan anak yaitu aspek aspek nilai agama dan moral, fisik motorik, kognitif, bahasa, sosial emosional, dan seni) dan memilih topik atau tema pembelajaran yang dekat dengan lingkungan dan budaya anak. Kegiatan masyarakat ini diikuti oleh 17 guru KB TK Inklusi Srawung Bocah. Adapun tahapan pelatihan yang dilakukan adalah perencanaan, pelaksanaan, pengamatan atau observasi, evaluasi dan revleksi, workshop ini berlangsung selama tiga bulan dalam mengembangkan maupun menerapkan strategi dalam menyusun rancangan rencana pelaksanaan pembelajaran untuk anak usia dini. Berikut alur rencana kegiatan pendabdian masyarakat.

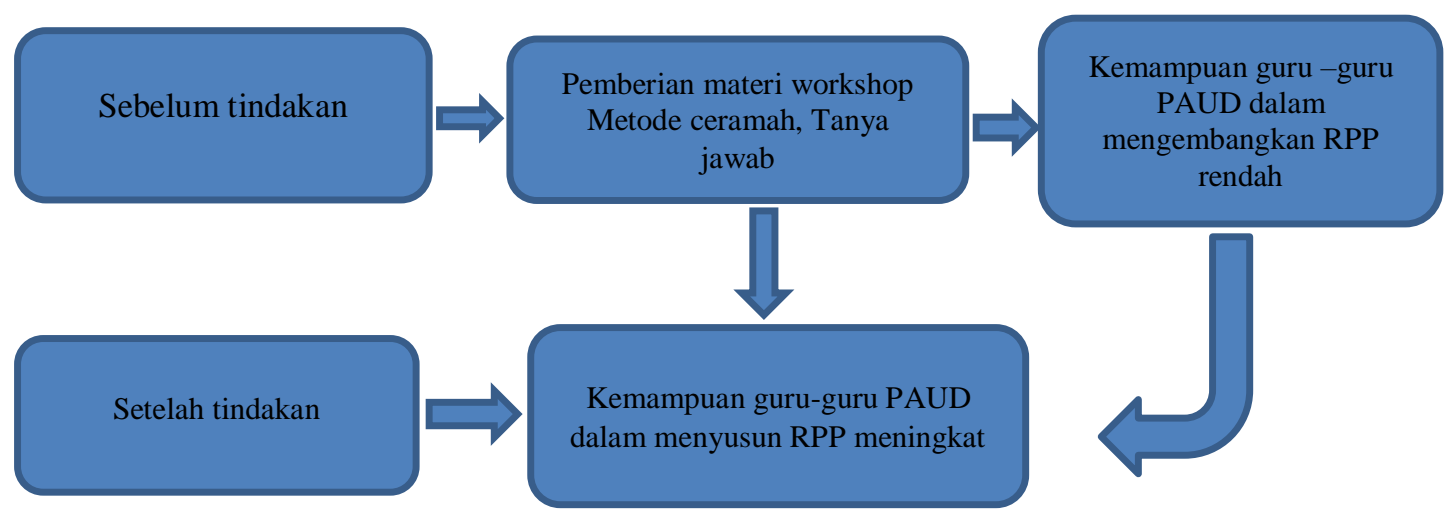

Gambar 1. Rencana Kegiatan

\section{Prosedur Pelaksanaan Pengabdian}

a. Perencanaan siklus 1 .

Pada siklus 1 kegiatan pengabdian direncanakan sebagai berikut: Pengapdi mempersiapkan pelaksanaan wordshop penyusunan dan pengembangan RPP dengan (1) membuat scenario kegiatan wordshop (membuat kepanitiaan, membuat rencana pelaksanaan wordshop, membuat bahan ajar atau modul, membuat lembar kerjanya. (2) Menyusun instrument proses pelaksanaan workshop dan dampak tindakan yang meliputi (lembar pengamatan jalannya workshop, lembar cacatan kejadian selama workshop berlangsung, pendapat guru dalam pelaksanaan workshop pengembangan RPP. (3) Membuat pedoman pengolah dan analisi data hasil pengamatan dan hasil test untuk melihat kemampuan guru dalam membuat RPP. (4) Menggunakan metode ceramah, metode Tanya jawab, dan metode penugasan.

\section{b. Tahap Pelaksanaan}

Pada tahap ini merupakan implementasi (pelaksanaan) dari semua rencana yang telah dibuat. Pada pelansanaan tindakan, pengandi melaksanakan tindakan sesuai dengan yang telah direncanakan yaitu melakukan kegiatan wordshop tentang bagaimana membuat rencana RPP secara mandiri sesuai dengan jadwal yang telah dipersiapkan oleh pengabdi secara konsisten. 
c. Tahap Pengamatan (observasi)

Pada tahap ini mencatat proses berlangsungnya kegiatan workshop menggunakan lembar pengamatan yang telah dibuat termasuk mencatat kejadian selama workshop berlangsung. Pada akhir workshop diberikan test tertulis penguasaan materi workshop yaitu tentang RPP menyusun RPP yang telah dibahas dalam workshop dan peserta mengumpulkan produk workshop yang berupa naskah RPP yang telah dibuat. Pengabdi menggunakan pertanyaan test yang telah dibuat pada rencana tindakan. Setelah data hasil pengamatan dan hasil test terkempul dilakukan pemerikasaan, pengolahan data dan analisis data sebagai bahan menarik kesimpulan efektif tidaknya jenis tindakan terhadap perubahan perilaku peserta setelah mengikuti workshop dengan cara membandingkan hasil analisis data dengan indicator keberhasilan tindakan.

\section{d. Evaluasi dan refleksi tindakan}

Pada tahap ini pengabdi melakukan kajian dan penilaian proses wordshop (data hasil pengamatan kegiatan workshop siklus 1 hasil dari perubahan pada guru dalam mengembangkan RPP data terkait nilai kemampuan guru-guru dalam membuat RPP siklus 1. Selanjutnya pengabdi membandingkan hasil pengamatan pelaksanaan workshop tentang pengembangan RPP dengan hasil test tentang kemampuan guru peserta workshop dalam memahami materi workshop. Apakah dengan metode workshop dapat meningkatkan kemampuan guru Paud dalam mengembangkan RPP atau belum. Tinggi rendahnya hasil test kemamampuan para guru-guru PAUD dalam membuat RPP yang diperoleh menunjukkan berhasil tidaknya kegiatan workshop. Hasil test tersebut dibandingkan dengan indicator keberhasilan tindakan yang menggunakan metode workshop yang telah ditetapkan sebelunya. Pada siklus perteme ternyata belum berhasil berarti kegiatan wordshop belum efektif. Dalam kondisi ini karena siklus pertama belum seperti yang pengabdi harapkan maka perlu dilanjutkan pada siklus ke dua dengan memperbaiki kekurangan pada kegiatan workshop pada siklus pertama. Perbaikan pada siklus kedua dilakukan dengan penambahan penjelasan dalam hal materi workshop dan adanya pendampingan intensif dalam pengembangan RPP.

Hasil dari siklus pertama ini menjadi masukan bagi pelaksanaan siklus kedua yang terdiri dari hasil perulangan ke empat langkah yang ada pada siklus pertama. Hal ini terjadi karena dimungkinkan setelah siklus pertama, pegabdi menemukan masalah baru atau masalah lama yang belum tuntas, sehinggga perlu dipecahkan melalui siklus selanjutnya. Dengan demikian, berdasar hasil tindakan atau pengalaman pada siklus pertama peneliti kembali melakukan langkah pada siklus kedua. 

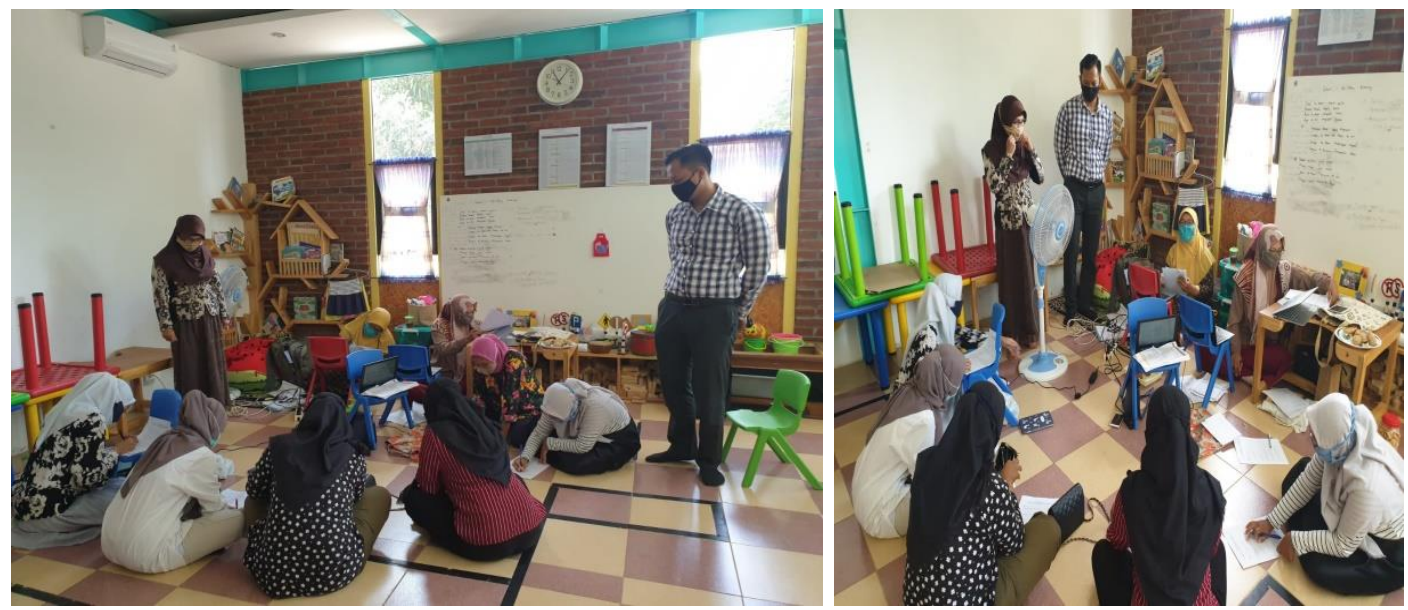

Gambar 2. Kegiatan pemberian materi workshop
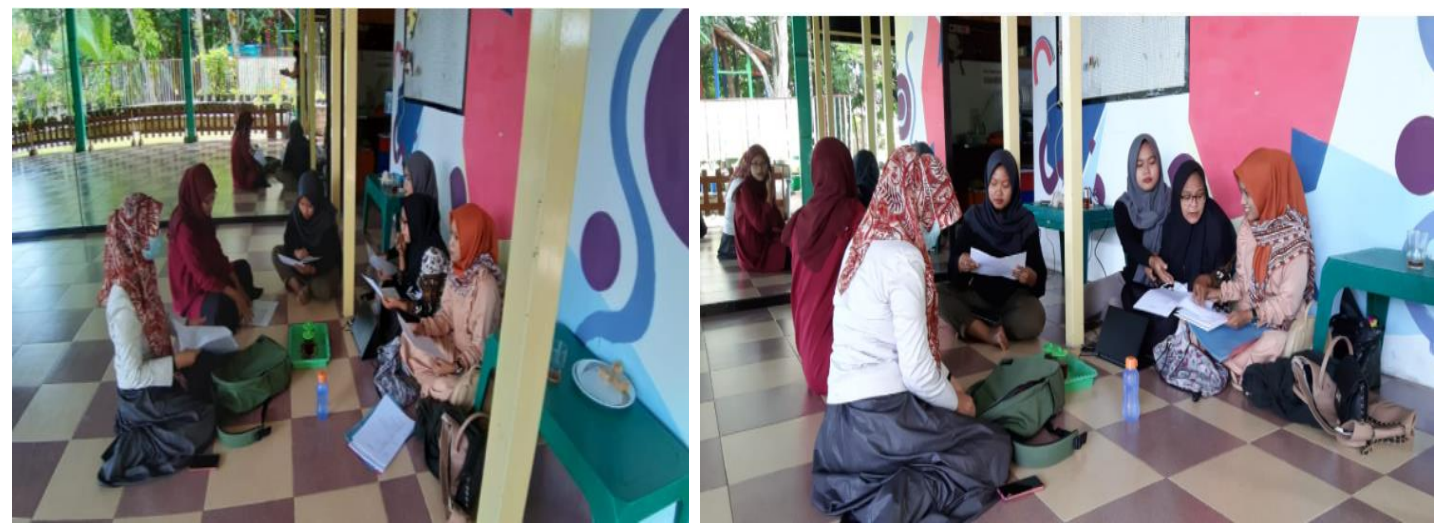

Gambar 3. Proses diskusi dalam persiapan penyusunan RPP

\section{Indikator keberhasilan tindakan:}

Indikator dalam keberhasilan dalam tindakan dilihat dari proses dan hasil yang dicapai dari wordshop ini yaitu 1) Pelaksanaan workshop (tahapan pelaksanaan wordshop sesuai dengan perencanaan yang telah di buat 2) Hasil tindakan workshop (jika 100\% guru-guru yang mengikuti workshop dapat membuat RPP nya dalam kategori baik.

\section{IMPLEMENTASI KEGIATAN DAN PEMBAHASAN}

Hasil pengabdian pada sajian data atau diskripsi hasil pengabdian siklus 1 Perencanaan siklus I. Pada siklus 1 kegiatan pengabdian direncanakan sebagai berikut: Pengabdi mempersiapkan pelaksanaan workshop penyusunan pengembangan rencana pelaksanaan pembelajaran (RPP), persiapan dan permasalahan dalam penyusunan Rancana pelaksanaan pembelajaran harian (RPP), penyusunan dan pengembangan RPP, tugas kelompok penyusunan RPP, presentasi kelompok, tugas individu menyusun mengembangkan RPP dilakukan selama 1 hari.

Pelaksanaan Workshop Pengembangan RPP siklus I. Pertemuan pertama, pemateri menerangkan mengenai persiapan dan permasalahan dalam penyusunan RPP, penyusunan dan pengembangan RPP. Pada akhir pertemuan pertama, pemateri memberikan penugasan penyusunan RPP kelompok. Selanjutnya para guru peserta workshop diminta untuk melanjutkan penugasan kelompok penyusunan RPP. Pada akhir pertemuan kedua, masing-masing kelompok diminta untuk mempresentasikan 
hasil penyusunan RPP secara kelompok kemudian dibahas oleh kelompok lainnya. Berikutnya para guru diminta untuk menyusun RPP secara individu dengan didampingi oleh pemateri. Pada akhir pertemuan ke 3, masing-masing guru peserta workshop diminta untuk mengumpulkan hasil penyusunan RPPH secara individu

Pengamatan workshop pengembangan RPP siklus I Pengamatan terhadap guruguru selama mengikuti workshop dilakukan dengan memperhatikan aspek-aspek sebagai berikut: a) Tingkat perhatian guru-guru PAUD pada kegiatan workshop.b) Keberanian mengemukakan pandapat selama workshop.c) Keberanian mengajukan pertanyaan.d) Keberanian menjawab pertanyaan.e) Kemampuan bekerjasama dalam tugas kelompok. f) Ketuntasan menyelesaikan tugas. g) Keberanian tampil presentasi di depan para peserta workshop h) Hasil Penyusuna RPP secara global.

Workshop penyusunan dan pengembangan RPP intansif, dengan topic yang relative sempit, danmenekankan pertukaran informasi, interaksi antar peserta, dan pembahasan yang sering bersifat tutorial dan cenderung teknis. Pada pelaksanaanya workshop siklus pertama, guru-guru PAUD peserta workshop masih belum memakai arti pengembangan rencana pelaksanaan pembelajaran (RPP). Sebagian kami amati masih membawa RPP dari hasil copi paste orang lain sehingga penyusunan belum disesuaikan dengan kondisi lingungan sekolah. Sedang pada siklus kedua hamper semua guru-guru ikut aktif dalam mengikuti workshop dengan memperhatikan kaidah penyususnan dan pengembangan RPP. Perbandingan hasil pengamatan pelaksanaan workshop siklus I dan siklus II sebagai berikut:

Tabel 1. Perbandingan kategorisasi keaktifan guru mengikuti workshop siklus I dan II

\begin{tabular}{|l|l|l|l|l|}
\hline \multirow{2}{*}{ Kategorisasi } & Siklus I & Siklus II & \\
\cline { 2 - 5 } & Jumlah & $\%$ & Jumlah & $\%$ \\
\hline Kurang aktif & 0 & 0 & 0 & $0,00 \%$ \\
\hline Cukup aktif & 3 & $17,64 \%$ & 0 & $0,00 \%$ \\
\hline Aktif & 6 & $35,29 \%$ & 4 & $23,53 \%$ \\
\hline Sangat baik & 8 & $47,05 \%$ & 13 & $76,47 \%$ \\
\hline Jumlah & 17 & $100 \%$ & 17 & $100,0 \%$ \\
\hline
\end{tabular}

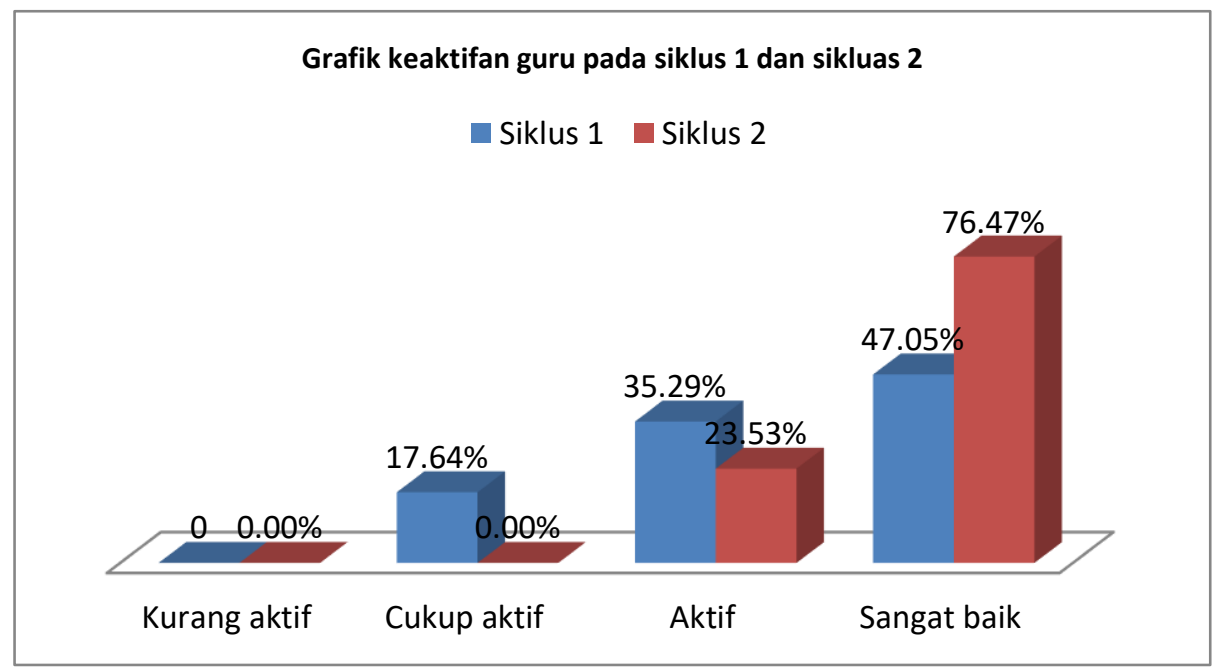

Tabel 4. Perbandingan siklus1 dan siklus 2 
Grafik pada gambar 4 menunjukkan adanya peningkatan keaktifan 1) Tingkat perhatian guru-guru PAUD pada kegiatan workshop 2) Keberanian mengemukakan pendapat selama workshop 3) Keberanian mengajukan pertanyaan, 4) Keberanian menjawab pertanyaan 5) Kemampuan kerjasama dalam tugas kelompok, 6) Ketentasan menyelesaikan tugas 7) Keberanian tampil presentasi di depan para peserta woekshop, dan 8) Hasil penyusunan RPP secara global dari aktif menjadi sangat aktif. Kualitas RPP yang dibuat oleh Gutu PAUD setelah dilakukan tindakan siklus II seluruhnya tergolong kategori baik.

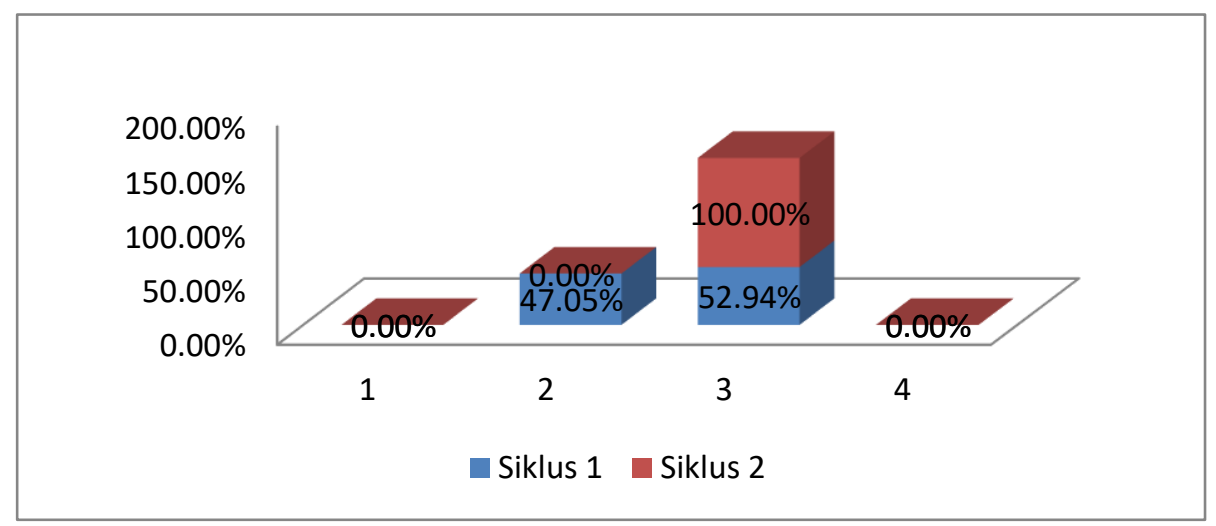

Tabel 5. Perbandingan Kualitas RPP, Siklus I dan Siklus I

Berdasarkan gambar grafik pada gambar 5 dapat diketahui bahwa terdapat peningkatan yang signifikan terhadap kualitas RPP dari siklus I sampai dengan Siklus II. Sehingga dapat disimpulkn bahawa ada peningkatan yang signifikan dalam menyusun dan mengembangkan RPP pada guru-guru KB TK Inklusi Srawong Bocah.

\section{KESIMPULAN}

Berdasarkan Kegiatan work shop dengan judul "Upaya Meningkatkan Kemampuan Guru PAUD dalam Menyusun Rencana Pelaksanaan Pembelajaran (RPP)", sebagaimana telah dipaparkan, maka penulis menyimpulkan bahwa metode work shop dapat meningkatkan kemampuan guru PAUD dalam membuat Rencana Pelaksanaan Pembelajaran (RPP) yang dapat menstimulasi seluruh aspek perkembangan anak. Melalui kegiatan work shop guru-guru mampu menumbuhkan kreativitas dalam merancang sebuah strategi dan media pembelajaran yang menarik bagi anak usia dini. Guru-guru mampu mengaplikasikan hasil work shop dalam pembelajaran di kelas masing-masing.

\section{DAFTAR PUSTAKA}

Ardiawan, I. K. N. (2020). Studi Peningkatan Kesiapan Guru Paud Terhadap Implementasi Kurikulum 2013 (Meta-Analisis). Widya Kumara: Jurnal Pendidikan Anak Usia Dini, 1(1), 33-39. https://stahnmpukuturan.ac.id/jurnal/index.php/JPAUD/article/viewFile/580/61 3

Anggreni, M. A., (2017). Kompetensi Guru Paud Di Kelurahan Balas. Buana Pendidikan. Jurnal Pendidikan Anak 2(1) 34-45 
Nazara, S. \& Ahmad, A., (2019). Perencanaan Pembelajaran Kurikulum 2013. Al Azkiya: Jurnal Ilmiah Pendidikan MI/SD, 4(2), 112-122. https://doi.org/10.32505/azkiya.v4i2.1191

Nurmajaya, B. F. (2021). Kompetensi Guru Dalam Merancang Rencana Pelaksanaan Pembelajaran. Jurnal Pengabdian 3(11) 89-95

Pamungkas, J., Hayati, N., \& Maryatun, I. B. (2016). Pengembangan Perencanaan Pembelajaran Paud Berbasis Budaya. Jurnal Pendidikan Anak, 5(2), 831-839. https://doi.org/10.21831/jpa.v5i2.12389

Susanto, D., Untari, E., \& Astuti, I. P. (2021). Efektivitas Think Pair Share (TPS) dan Pembelajaran Langsung dengan Talking Stick (TS) ditinjau dari Prestasi dan Kemandirian Belajar. DIKSI: Jurnal Kajian Pendidikan dan Sosial, 2(2), $77-85$.

Syaodih, E., Kurniawati, L., Handayani, H., Setiawan, D., \& Suhendra, I. (2020). Pelatihan Keterampilan Guru dalam Membuat Perencanaan Pembelajaran Sains Anak Usia Dini. Pengabdian Pada Masyarakat, 5(2), 519-528.

Sutarto, S., Pd, M., Syarifuddin, S. P., \& Pd, M. (2013). Desain Pembelajaran Matematika. Yogyakarta: Samudra Biru.

Syarifuddin, S., Nugroho, P. B., Fadhli, M., Murtalib, M., Mutmainah, M., Muchlis, M., ... \& Hadi, A. M. (2021). Sosialisasi Aplikasi Pembelajaran Jarak Jauh dan Pengembangan Bahan Ajar bagi Dosen, Guru, dan Mahasiswa di Era Pandemi Covid-19. Bima Abdi: Jurnal Pengabdian Masyarakat, 1(1), 30-36.

Tirtayani, L. A., Sujana, I. W., \& Wirabrata, D. G. F. (2019). Pelatihan penyusunan perangkat pembelajaran menggunakan pendekatan saintifik. Widya Laksana, $8(2)$, 151-160. https://ejournal.undiksha.ac.id/index.php/JPKM/article/view/18316

Undang-Undang Guru dan Dosen (Undang-Undang Republik Indonesia Nomor 14 Tahun 2005). 